\title{
BIOCHEMICAL AND IMMUNOLOGICAL CHARACTERIZATION OF ANTHRAX SPORE VACCINE IN GOAT
}

\author{
P. Roy, M. M. Rashid, M. J. Ferdoush, M. Dipti, M. G. A. Chowdury, M. G. Mostofa, S. K. Roy, M. A. H. N. A.
} Khan and M. M. Hossain*

Department of Pathology, Faculty of Veterinary Science, Bangladesh Agricultural University, Mymensingh-2202, Bangladesh

\begin{abstract}
Anthrax is caused by Bacillus anthracis bacterium and an acute infectious febrile septicemic disease of all warm-blooded animals including human. It is a disease of major economic importance in ruminant specially in goat characterized principally by a rapid fatal course followed by sudden death. The present investigation was under taken to determine the biochemical characterization of anthrax spore vaccine bacteria and to determine the immunological response in goat after anthrax vaccination. Anthrax vaccine was collected from local government veterinary hospital, Mymensingh which was prepared by LRI. The goats were selected from different regions of Bangladesh. The used methods were culture of vaccine bacterial sediment in different media, staining of bacteria with Gram's stain, and sugar fermentation tests for biochemical characterization of anthrax vaccine bacteria. Slide agglutination test and indirect ELISA tests were performed for immunological response after vaccination. Morphologically anthrax vaccine bacteria was gram positive rod shaped or short chain in anthrax vaccine sediment, culture in nutrient agar and nutrient broth. The anthrax vaccine bacteria fermented three sugars (dextrose, maltose and sucrose) and produced only acid but did not ferment two sugars (lactose and mannitol). Immunuglobulin of collected serum (Day0, Day30 and Day90) also agglutinated anthrax antigen on Day 30 and Day 90 of post immunization and onwards. Indirect ELISA provided evidence that immunization of captive and free range goat generated level of anti anthrax $1 \mathrm{gG}$ antibody response at Day 0 (OD Value $0.5474 \pm 0.0466$ ) of immunization and reached its peak at Day 30 (OD Value 0.9604 \pm 0.0936 ) and maintained that level up to the end of the study (Day 90, OD Value $1.217 \pm 0.1129)$. After vaccination, immunological response was found in goat. However whether this immune response can protect natural anthrax infection need to be evaluated through challenge dose of fields isolates of Bacillus anthracis in future.
\end{abstract}

Key words: Biochemical test, anthrax vaccine, immune response, goat

\section{INTRODUCTION}

Anthrax is an economically important and killer disease of animals in Bangladesh (Murshidul, 2012). There are three forms of illness in cattle such as per acute: sudden death and rapidly fatal course; acute: high temp. $\left(107^{\circ} \mathrm{C}\right)$, bloody discharge from orifices and sub acute-chronic: edematous swelling. Anthrax is a zoonotic disease (disease that can affect both man and animals). In humans, it can take five forms: cutaneous, respiratory, intestinal, septicemic and meningial. The cutaneous or skin form occurs when anthrax spores invade a cut or abrasion. Initially the site will itch followed by swelling and discoloration of the affected area (Weiss et al., 2007, OIE, 2008)

Reported and published findings shows that there were 14 outbreak and 140 animals and 273 human cases were affected by anthrax during Aug. 2009-Oct. 2010 in Bangladesh. Anthrax in animals was prevailing in Bangladesh but it has got more importance after human was affected by handling anthrax affected cattle and goat. For the control of anthrax in goat, anthrax spore vaccine prepared by Livestock Research Institute (LRI) Mohakhali, Dhaka is now being used.

The master seed is F-24 strain of B. anthracis, originated from Australia. The dose is $0.5 \mathrm{ml}$ subcutaneously per goat/year. The LRI claims that these vaccines can give protection for 6 months. In each lot or batch of vaccine, quality control is needed. As a part of quality control and to prove this claim of LRI anthrax vaccine for 6 months duration of immunity, the more data in relation to immune response are inevitable. Therefore, the present experiment was designed to determine the biochemical characterization of anthrax vaccine bacteria along with the anti anthrax immune response after immunization of goat.

\section{MATERIALS AND METHODS}

This study was conducted at the Department of Pathology, Faculty of Veterinary Science, Bangladesh Agricultural University, Mymensingh during the period from June 2012 to May 2013.

*Corresponding e-mail address: mmhossain04@yahoo.com.au

Copyright (C) 2013 Bangladesh Society for Veterinary Medicine

All rights reserved 0277/2013 


\section{P. Roy and others}

\section{Collection of vaccine:}

Anthrax vaccine is supplied as $100 \mathrm{~m} 1$ bottle prepared by Livestock Research Institute, Mohakhali, Dhaka. The master-seed of this vaccine is living spores of the non-capsulated attenuated Sterne F-24 strain of B. anthracis originated at Australia. Five bottles anthrax vaccine had been collected from local government veterinary hospital, Mymensingh during research period.

\section{Selection of experimental animals:}

Apparently healthy and previously unvaccinated goat of both sexes weighing about 5 to $10 \mathrm{~kg}$ from BAU, Mymensingh $(n=5)$, Pabna $(n=5)$ and Tangail $(n=5)$ (semi-changeable climatic zone), Sathkhira (climatic change prone delta region) $(n=5)$ goat farm were used in this study to evaluate the presence of anti anthrax antibody in the serum samples after vaccination.

\section{Vaccination/Immunization of experimental goat}

According to the instruction of manufacturer, $0.5 \mathrm{ml}$ of anthrax vaccine was injected subcutaneously $(\mathrm{S} / \mathrm{C})$ in goats of different regions. The blood sample was collected at Day 0, Day 30 and Day 90 of vaccination.

\section{Collection of serum from experimental goat}

About $5 \mathrm{ml}$ of blood was collected from jugular vein puncture using disposable plastic syringe in $15 \mathrm{ml}$ Falcon tube. The blood was left to clot overnight in refrigerator at $4{ }^{\circ} \mathrm{C}$ in slanting position. The sera were decanted into Eppendorf tubes and the centrifuged at $2000 \mathrm{rpm}$ for 10 minutes. The supernatant of these sera was again decanted into Eppendorf tube and stored at $-20^{\circ} \mathrm{C}$ until use.

\section{Isolation and identification}

A total of $5 \mathrm{ml}$ vaccine was taken in Eppendorf tube and centrifuged at $3000 \mathrm{rpm}$ for 10 minutes. Then the supernatant was removed. The sediment was washed by PBS $(1 \mathrm{ml})$ for 3 times and was used for bacteriological culture. Gram's stain was performed to observe the morphology of anthrax spore vaccine after sedimentation. After that this anthrax bacterial sediment was cultured in nutrient broth and nutrient agar plates. Personal protection was taken to culture anthrax vaccine bacteria. The culture of bacteria in broth and agar from anthrax vaccine were put into $10 \%$ formalin for 24 hours before disposal.

\section{Morphological characterization}

A small amount of bacteria from nutrient agar and broth was taken by bacteriological loop on clean glass slides. One drop of distilled water was added then it was mixed properly. Later the slides were first air dried and then fixed with gentle heat. Crystal violet was applied on the smear of slide for $2 \mathrm{~min}$. The slide was washed in water. Gram's iodine was applied for $2 \mathrm{~min}$. Iodine was applied on slide and tipped off but did not wash. The slide was decolorized with a few drops of acetone for 5 seconds. It was washed thoroughly in water. The slide was stained by counter stain with $0.5 \%$ safranin for $1 \mathrm{~min}$. The slides were washed and stood on end to drain for air dry. The slides were examined with immersion oil in high power objectives.

\section{Biochemical characterization}

The sugar fermentation test was performed by inoculating $5 \mathrm{ml}$ of nutrient broth culture of the organism into the tubes containing different sugar media and incubated for 24 hours at $37^{\circ} \mathrm{C}$. Acid production was indicated by the color change from red to yellow of the medium and the gas production was noted by the appearance of gas in the inverted Durham's tube.

\section{Slide agglutination test}

The test sera were diluted by 1:10, 1:100 and 1:1000. The test was performed by placing a drop of diluted antigen and a drop of diluted serum on a slide. Then two drops were mixed slowly and kept at room temperature and examined every 5 to 10 minutes for evidence of clumping followed by microscopic examination. The same procedure was done for every sample and compared with negative serum. The slide agglutination result graded as ,,++++++ and \pm according to clumping formation in 5 minutes, 7 minutes, 10 minutes and after 10-15 minutes.

\section{I-ELISA (Indirect Enzyme Linked Immunosorbent Assay) Antigen coating to ELISA plate}

Each well of a plate was coated with the antigen by pipeting $50 \mu 1$ of the antigen dilution and $50 \mu 1$ of PBS. 
The plate was covered with an adhesive plastic and incubated for 1 hour at $37^{\circ} \mathrm{C}$. The solutions are removed by flicking the plate over a sink and washing was done in PBS-Tween-20 (0.05\%) for 3 times. The remaining drops are removed by patting the plate on a paper towel.

\section{Blocking}

The remaining protein-binding sites in the coated wells was blocked by adding $150 \mu$ l blocking buffer, per well. The plate was incubated at $37^{\circ} \mathrm{C}$ for 90 mintues. The plate was washed $3 \mathrm{x}$ with PBS Tween-20 $(0.05 \%)$.

\section{Incubation with primary and secondary antibody}

One hundred microliter of diluted primary antibody was added to each well. The plate was incubated for 1 hour at $37^{\circ} \mathrm{C}$. The plate was washed $3 \mathrm{x}$ with PBS Tween-20 (0.05\%). $100 \mu \mathrm{l}$ of HRP labeled anti-bovine antibody (1:5000) was added each well and incubated for $45 \mathrm{~min}$ at $37^{\circ} \mathrm{C}$.

\section{Detection}

TMB solution $100 \mu 1$ per well was added and incubated at room temperature in the dark for 15 mintues or until turn to green color. To stop the reaction, $50 \mu 110 \% \mathrm{H}_{2} \mathrm{SO}_{4}$ was added to each well which give yellow color. Then the plate was read at $450 \mathrm{~nm}$ (Fatema , 2011).

\section{RESULTS}

The following results represent the biochemical and immunological characterization of anthrax vaccine in goat. The results also included the isolation and identification of anthrax bacteria (Bacillus anrhracis) from anthrax vaccine. Anthrax vaccine was collected from local government veterinary hospital, Mymensingh. The vaccine, $0.5 \mathrm{ml}$ volume was delivered through S/C route of goats of BAU ( Mymensingh), Pabna and Tangail (semi-changeable climatic zone) and Satkhira (climatic change prone delta region). The serum was collected at Day 0, Day 30 and Day 90 of vaccination from different regions, preserved at $-20^{\circ} \mathrm{C}$ and an indirect ELISA was used to evaluate degree of immune response against anthrax spore vaccine. The vaccine was also characterized by morphological and biochemical analysis.

\section{Isolation and identification \\ Cultural examination}

A loop full bacterium from the vaccine sediment, nutrient agar plate and nutrient broth was smeared on to clean glass slide, dried up and stained with Gram's stain. Smears showed rod shaped, gram positive bacteria (Fig. 1) and examined at high power (100X) microscopic field. After overnight incubation at $37^{\circ} \mathrm{C}$ from each positive subculture colony the bacteria produced irregular, raised, dull, opaque and greyish white with 'frosted glass' appearance on nutrient agar (Fig. 2.).

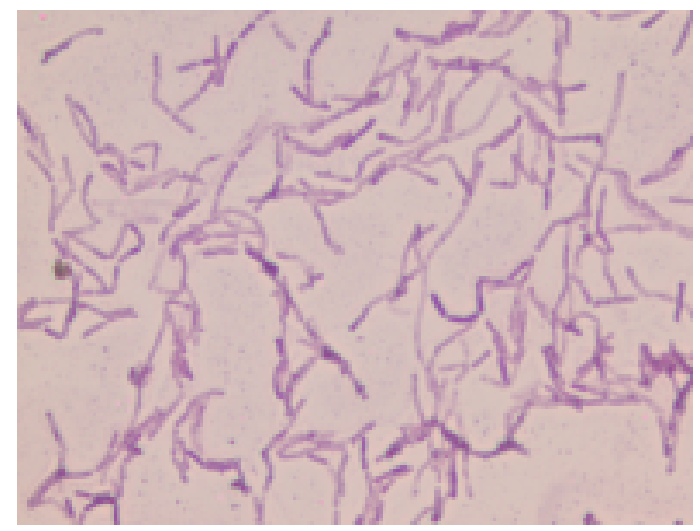

Figure 1. Smear prepared from fresh culture of Bacillus anthracis spore vaccine on nutrient agar and stained with Gram's stain showed gram- positive rod shaped bacteria appear as single to short-chained bacilli with blunted ends (100X).

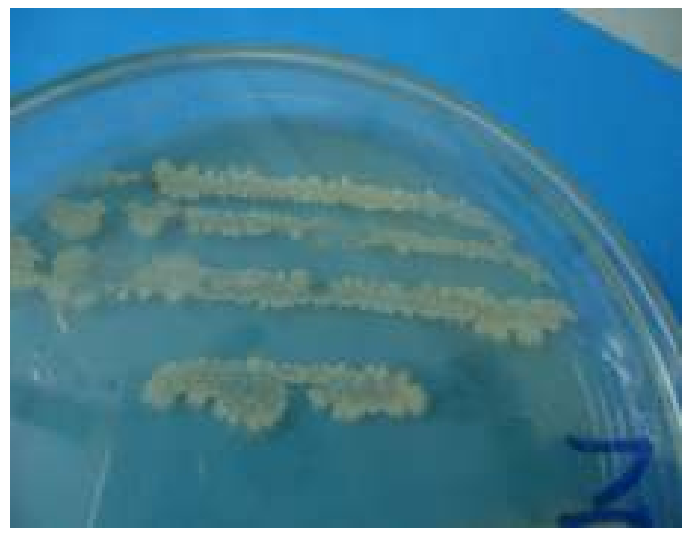

Figure 2. Creamy white colony of $B$. anthracis was found (after overnight incubation at $37^{\circ} \mathrm{C}$ ) in nutrient agar (NA) media. 


\section{P. Roy and others}

The edge of the colonies was curled with long interlacing chains of Bacillus resembling curly looks. This colony of $B$. anthracis was found as like creamy white.

Anthrax vaccine bacteria were inoculated to nutrient broth. After overnight incubation at $37^{\circ} \mathrm{C}$ in nutrient broth 'cotton wool' like bacterial growth were observed.

\section{Biochemical tests}

After confirming the purity of the positive isolates from anthrax vaccine bacteria, sugar fermentation tests were performed for $B$. anthracis. Anthrax vaccine bacteria from nutrient agar were used for five basic sugar fermentation tests. They fermented three sugars (dextrose, maltose and sucrose) but did not ferment two sugars (lactose and mannitol) and produced acid (Table 1). Acid production was indicated by the color change from reddish to yellow and the gas production was noted by the appearance of gas bubbles in the inverted Durham's tubes (Rahman, 1996).

Table 1. Biochemical characteristics of B. anthrncis cultured from anthrax vaccine

\begin{tabular}{|c|c|c|c|c|c|}
\hline \multicolumn{5}{|c|}{ Sugar fermentation test (acid and gas production) } & $\begin{array}{l}\text { Identified } \\
\text { organism }\end{array}$ \\
\hline Dextrose & Sucrose & Lactose & Maltose & Mannitol & $\begin{array}{c}\text { Bacillus } \\
\text { anthracis }\end{array}$ \\
\hline$+\mathrm{ve}$ & + ve & -ve & $+\mathrm{ve}$ & -ve & \\
\hline
\end{tabular}

$\{+\mathrm{ve}=$ Positive reaction $=$ acid and gas production, $-\mathrm{ve}=$ Negative reaction $=$ no acid and gas production $\}$.

\section{Slide Agglutination Test}

Table 2 describes the results of slide agglutination test of tested sera and anthrax vaccine bacteria. In this study, slide agglutination tests were done for observing the clumping/agglutination between antigen (vaccine strain) and test sera. The agglutination was graded as $+++=$ more agglutination within 5 minutes, $++=$ agglutination within 7 minutes, $+=$ less agglutination within 10 minutes, $\pm=$ agglutination within $10-15$ minutes, $-=$ absence of agglutination even after 15 minutes at room temperature. The antibody response of goat of different region at Day 0 was very minimum $( \pm$ to + ). The antibody response started rising at Day $30(++$ to +++$)$ until Day 90 $(+++)$. However the striking difference of slide agglutination test was not found in goat of sem-changeable climatic zone (BAU (Mymensingh), Pabna and Tangail) with that of climatic change prone delta region (Satkhira) goats (Fig. 3.a,b,c and d).

Table 2. Results of the slide agglutination test using sera from vaccinated goats

\begin{tabular}{|l||c|c|c|}
\hline Samples & \multicolumn{3}{|c|}{ Dilution of sera } \\
\hline $\mathrm{N}=20$ & $1: 10$ & $1: 100$ & $1: 1000$ \\
\hline Day 0 & \pm & \pm & - \\
\hline Day 30 & ++ to +++ & ++ & + \\
\hline Day 90 & +++ & ++ & + \\
\hline
\end{tabular}

From each region of experimental area 5 samples were tested and total samples were 2

$+++=$ more agglutination within 5 minutes,

$++=$ agglutination within 7 minutes,

$+=$ less agglutination within 10 minutes,

$\pm=$ agglutination within $10-15$ minutes,

- = absence of agglutination even after 15 minute

\section{Indirect ELISA}

An indirect ELISA protocol was applied in order to measure the level of serum anti anthrax IgG immune response in goat (Fig. 4). Immunization against anthrax proved to be effective in terms of the specific antibody response. The OD value was measured using ELx800 reader with an interface filter of $450 \mathrm{~nm}$. A baseline OD value in ELISA protocol $0.5474 \pm 0.0466$ was considered as control/negative response based on the average reactivity of control serum at 1:1000 dilution following reading. 


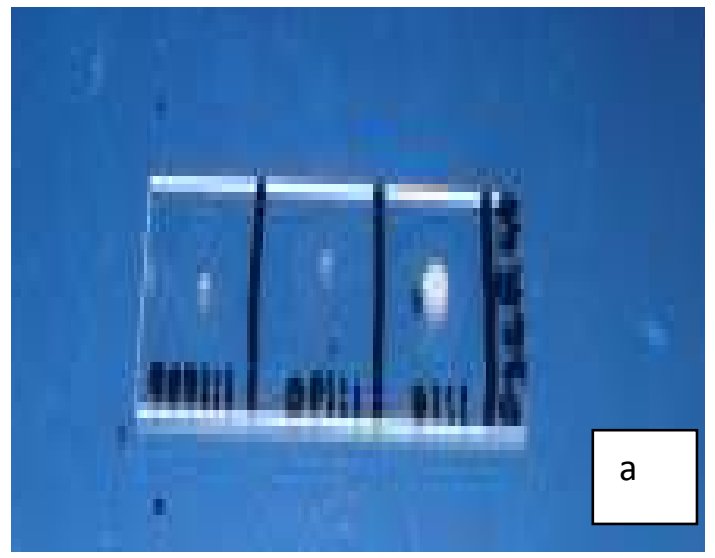

Figure 3. Clumping of particulate antigen (vaccine strain) after 5 mins (Day 30 of goat from Sathkhira)

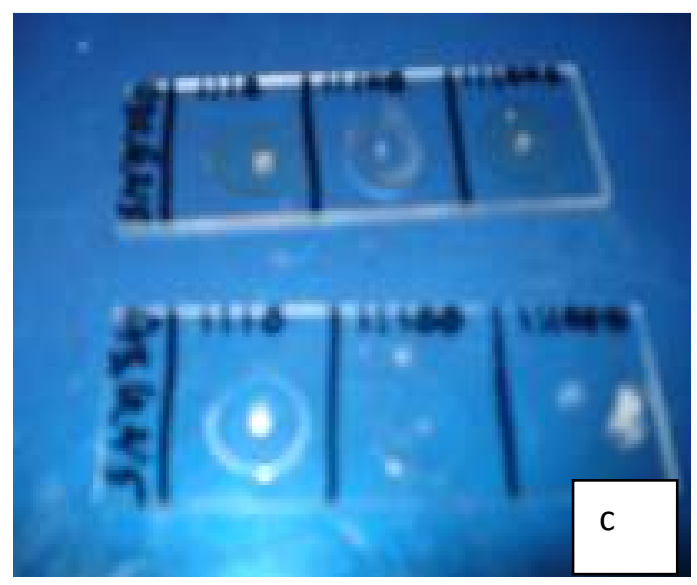

Figure 3. Clumping of particulate antigen(vaccine strain) after 10 mins (Day 30, Day 90 of goat from Mymensingh)

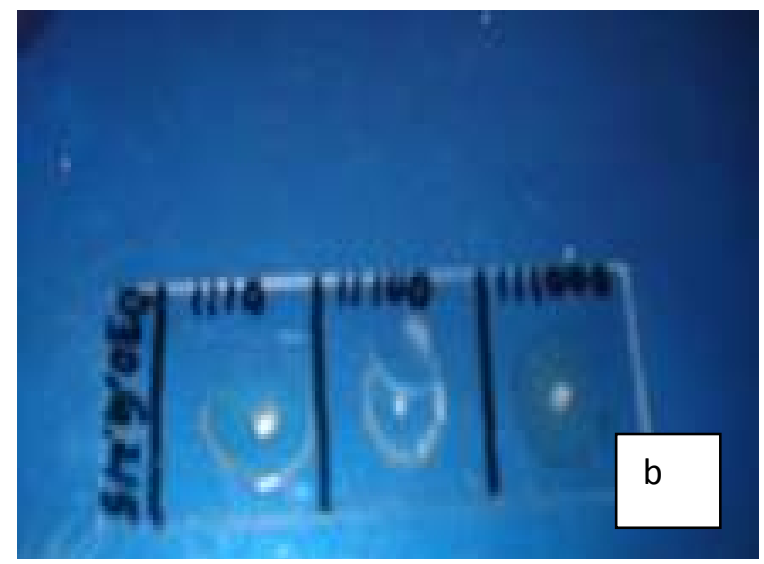

Figure 3. Clumping of particulate antigen (vaccine strain) after 7 mins (Day 30 of goat from Pabna)

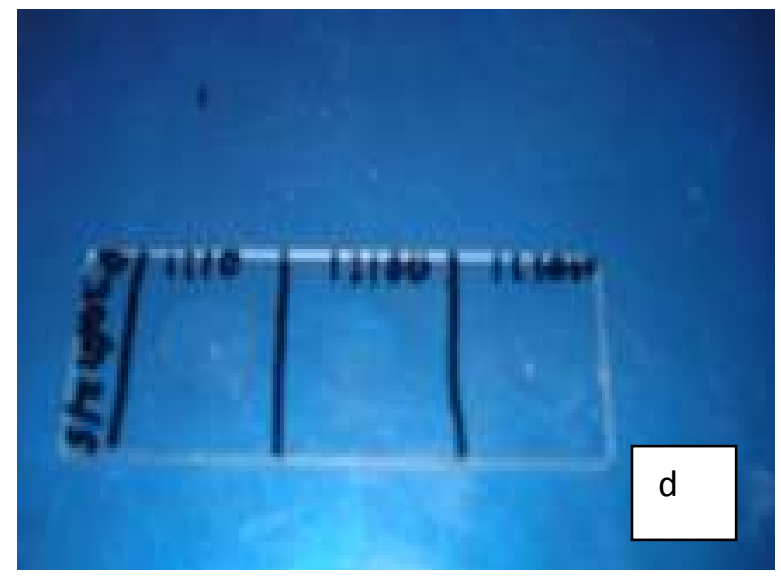

Figure 3. Comparison of clumping reaction with negative test sera (absence of clumping) (Day 0 of goat from Tangail)

Table 3. The results of ELISA tests in sera from goats after vaccination

\begin{tabular}{|lrrrrrr|}
\hline \multicolumn{1}{|c}{ Serum type } & \multicolumn{5}{c|}{ ELISA OD values of serum samples } \\
\hline \multicolumn{1}{|c}{ Post vaccination } & S-1 & S-2 & S-3 & S-4 & S-5 & Mean \pm SD \\
\hline Day 0 & 0.543 & 0.489 & 0.523 & 0.57 & 0.612 & $0.5474 \pm 0.0466$ \\
Day 30 & 0.892 & 0.989 & 0.891 & 0.918 & 1.112 & $0.9604 \pm 0.0936$ \\
Day 90 & 1.119 & 1.342 & 1.089 & 1.221 & 1.314 & $1.217 \pm 0.1129$ \\
\hline
\end{tabular}

The value above $0.5474 \pm 0.0466$ was considered as positive response and used in this study. The early immune response of anti anthrax $\operatorname{IgG}$ response was detected in day $30(0.9604 \pm 0.0936)$ of immunization and steadily

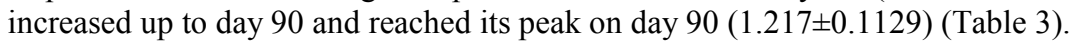




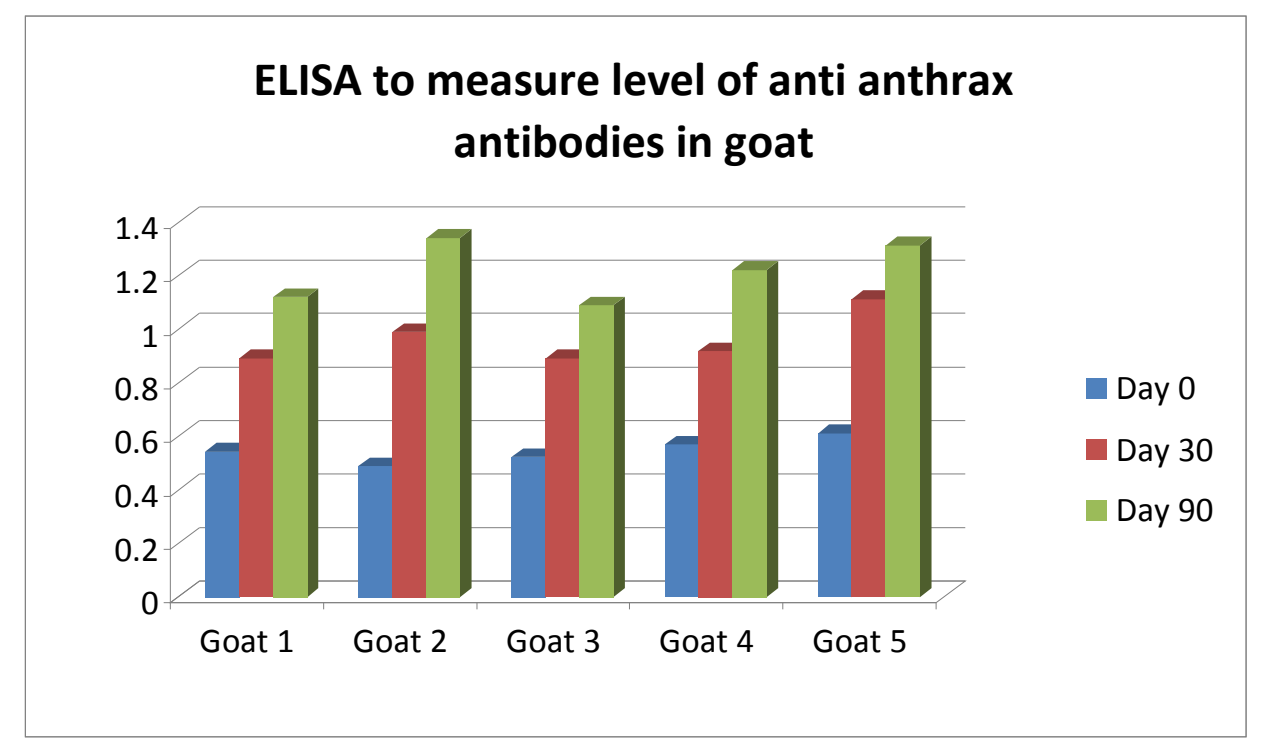

Figure 4. Serum anti anthrax IgG antibody response in goats as measured by indirect ELISA. Level of anti anthrax IgG was detected in blood 30 days after immunization and the level gradually increased until day 90 of immunization.

\section{DISCUSSION}

The study was undertaken for the biochemical and immunological characterization of anthrax vaccine in goat. Anthrax is now an emerged zoonotic disease of Bangladesh and it is enzootic also for long time (Ahmed et al., 2010).

In this research, $B$. anthracis isolates were isolated from anthrax vaccine by culturing in nutrient agar and nutrient broth media. Cultured anthrax bacteria were confirmed by five basic sugar fermentation tests, cultural growth characteristics in other media like nutrient agar and nutrient broth. All the works of this study conducted for the isolation and identification of $B$. anthracis from anthrax vaccine were corresponded with the mentioned results of "Manual for Laboratory Diagnosis of Anthrax" by World Health Organization (WHO), 2003 and "OIE Terrestrial Manual 2008" by World Organization for Animal Health (OIE) and "Basic Laboratory Protocols for the Presumptive Identification of Bacillus anthracis" by Centers for Disease Control and Prevention (CDC), 1994.

Smears from anthrax vaccine bacterial sediment, culture from nutrient agar and nutrient broth of vaccine strain were made for observing phenotypic characteristics which showed typical morphology of Bacillus anthracis that was gram-positive rod-shaped bacteria appeared as single to short-chained bacilli with blunted ends corresponded with the findings of Sterne et al. (2005).

Slide agglutination test was performed as a part of this study for observing the clumping/agglutination between antigen (vaccine strain) and test sera. At RT, the clumping appeared as little white agglutinates after 5 minutes, which was more dense after 10 minutes.

Then it was compared with negative test sera which was collected from goat (Day 0). There was no clumping in case of negative test sera. This agglutination test proved that the test sera contained specific antibody against anthrax antigen which was absent in negative test sera. This study also provided evidence that the antibody remained in goat against the vaccine strain reacted with the vaccine strain of anthrax antigen. These test were corresponded with the findings of Kok et al. (1996).

An Indirect ELISA protocol was adopted in order to measure the level of serum anti anthrax IgG immune response in goat. Immunization against anthrax proved to be effective in terms of the specific antibody response. The OD value measured using ELx800 reader with an interface filter of $450 \mathrm{~nm}$. 
A baseline OD value in ELISA protocol 0.5474 was considered as control/ negative response based on the average reactivity of control serum at 1:1000 dilution following reading. The value above 0.5474 was considered as positive response and used in this study. The early immune response of anti anthrax IgG response was detected in day $30(0.9604)$ of immunization and reached its peak on day 90 (1.217) during the study period corresponded with the findings of Rajalakshmi et al. (2010).

Vaccine strain of $B$. anthracis cannot induce any clinical anthrax, however, comparison of biochemical test (sugar fermentation test) of vaccine strain of bacteria was included in this study as at every lot or batch of produced vaccine, the quality control is needed in terms of morphological and biochemical nature of vaccine candidate as well as its immune response. Anthrax vaccine prepared by LRI, Mohakhali, Dhaka is operative in aspect of morphological, biochemical characterization and immunological response. In this study, immunological response determined by slide agglutination test and ELISA in goats of different region of semi-changeable climatc zone (BAU (Mymensingh), Pabna and Tangail) and climatic change prone delta region (Satkhira) goats were not detected. However whether this immune response is sufficient to protect natural cases of anthrax infection need to be evaluated in future by challenge dose of field isolates of B. anthracis.

\section{ACKNOWLEDGEMENT}

The authors are grateful to Planning Commission, Bangladesh for financial support of this research work.

\section{REFERENCES}

1. Ahmed N, Sultana Y, Fatema DSM, Ara K, Begum N, Mostanzid SM and Jubayer S (2010). Anthrax: An emerging Zoonotic disease in Bangladesh. Bangladesh Journal of Medical Microbiology 04 (01):46-50.

2. Centers for Disease Control and Prevention (CDC) (1994). Summary of notifiable diseases, 1945-1994. Morbidity and Mortality Weekly Report. 43: 70-78.

3. Fatema TZ (2011). Standardization of an ELISA protocol for the detection of IgG antidody in cattle against anthrax vaccine. MS Thesis submitted to Dept. of Pathology, BAU, Bangladesh. pp. 45-55.

4. Kok TW, Worswick D and Gowans E (1996). Some serological techniques for microbial and viral infections. Mackie \& McCartney Practical Medical Microbiology. 14th ed.p. 179-204.

5. Murshidul A (2012). Epidemiological investigation of anthrax in Bangladesh. MS Thesis submitted to Dept. of Microbiology, BAU, Bangladesh. pp 23-48.

6. OIE Terrestrial Manual (2008). OIE listed diseases and other diseases of importance to international trade. Part-2, Chapter 2.1.1.-Anthrax. pp-135-144.

7. Rahman MM (1996). Bacillus, Chapter-3: Systematic Bacteriology. In: Bacteriology (19, Edition), Published by Lumah-Sakib Parakashoni, Mymensingh-2202, Bangladesh.PP. 77-80.

8. Rajalakshmi A, Renugadevi TS and Gunasekaran S (2010m). Effect of anthrax spore vaccine in cattle and goat. International Journal of Pharmaceutical Sciences Review and Research. Volume 3, Page 22.

9. Sterne M, Cote CK, Rossi CA, Kang AS, Morrow PR, Lee JS and Welkos SL (2005). The detection of protective antigen (PA) associated with spores of Bacillus anthracis and the effects of anti-PA antibodies on spore germination and macrophageinteractions. Microbial-Pathogenesis. 38(5/6): 209-225 .

10. Weiss MM, Weiss PD and Weiss IB (2007). Anthrax vaccine and public health policy. American Journal of Public Health. 97(11): 1945-1951.

11. WHO (2003). Manual for Laboratory Diagnosis of Anthrax. Published by World Health Organization (WHO), regional office for South-East-Asia, New Delhi. 